\title{
Selection committees for consultant posts in the National Health Service
}

\author{
Barbara J. Cohen
}

Neville Lodge, 14, Astons Road, Moor Park, Middlesex HA6 2LD, UK.

There are times when the adage, 'A camel is a horse designed by a committee' seems particularly appropriate to the question of selection for senior posts in medicine. This is not to imply that those who survive the committee process and are awarded the crown of a lifetime's post as a consultant are undeserving of their elevation, but rather that the procedure is an unwieldy and arguably inefficient one, and that a little streamlining would not come amiss.

During the course of running interviewing skills training for senior registrars with consultant selection as their goal, I have been deeply exercised by the some of the things I have learned. The 'balance' having not yet been achieved, there are inevitably cases of time-expired senior registrars chasing, in some specialties, too few consultant posts. And what happens in these cases? First, they are often obliged by virtue of their contract (limping on in six-month stages) to apply for every advertised job in their specialty, wherever it is, and irrespective, it would seem, of other considerations - such as spouse's job, children's educational needs, the price of housing and so forth. Then it is encumbent upon the candidate to pay a lengthy visit - sometimes more than one - to investigate the job, the hospital and one's putative colleagues. If he or she is working in London and the advertised job is in Dumfries, the demand on the candidate's time, purse and energy can be considerable, and all this takes place before it is even known whether one is on the shortlist. There are cases, therefore, of highly qualified practitioners scurrying around the country, in a desperate and demoralising search for acceptance. The vicious circle element is obvious. How can you show clear enthusiasm and motivation for Netherthorpe district general hospital when you and everyone else knows that it is your twentieth application and that it is not this job, but any job that you seek? How can you tolerate the

Correspondence: B.J. Cohen, B.A.(Hons.) A.F.B.Ps.S., C.Psychol.

Received: 24 July 1989 disillusionment of failing once again, of salvaging pride and self-respect, so that your next application is not tainted by residual bitterness from your previous ones? How reasonable is it to have a professional, often in his or her forties, in a constant state of career and domestic uncertainty? (Should we decorate the house? - but we might be moving to Wales - Should we accept Timothy's offer of a place at St. Paul's? - But we might be moving to Cornwall, etc., etc.). How reasonable is it for patients and colleagues in an already stressed Health Service that so many senior registrars are absent, chasing round the country rather than doing the job for which they are being paid?

All this needs to be dealt with for the sake of efficiency and of morale. Let us assume, however, that our candidate has surmounted this hurdle and that he or she makes it to the Advisory Appointments Committee, preceded, perhaps, by that infamous 'Trial by Sherry'. At the real 'interview' the candidate is confronted by an august body of men and women. Some, quite possibly, he or she may already know - perhaps having worked with them in the past, perhaps having met them before on an earlier, unsuccessful panel. The applicant is now at the mercy of the dynamics which come into play whenever panel interviewing is involved.

Basically, a committee is not a very effective machine for selecting people. There is a danger that once a number of interviewers are simultaneously involved, the focus on the candidate becomes somewhat blurred by virtue of the interplay within the board. It is not unknown for panel members to use the situation to score points off each other, to wish to impress their colleagues perhaps more by the cleverness of their questions than to establish the maximum amount of information from the candidate. There is a risk, too, that the selectors may not always pay full attention within the interview, perhaps concentrating on formulating their own questions, or on hastily flicking through the curriculum vitae before them for inspiration or clarification. The information that tends to emerge in such interviews is, at best, patchy. It seems to consist of questioning about some aspects of the 
candidate's recent career, and a great many hypothetical posers of the 'how do you feel about controlling a budget?' variety. The difficulty with hypothetical questions, firstly, is that a candidate may well give the theoretically correct response, but that does not necessarily indicate that in real life such a course of action would in fact be followed. Secondly, and more commonly, the hypothetical question may not be sufficiently clear cut to allow for a true considered response. Then, the candidate may find him or herself hedging, 'well, it depends on the circumstances', 'I would need more information', etc., and the interviewer is in danger of writing the applicant off as feeble or indecisive when in fact, what the candidate is struggling against is the inept questioning of the interviewer.

And this brings us to the whole question of interviewer technique. The interview is still far and away the most commonly used method for assessing a person's suitability for a job, and yet it is not really a very effective one. Different interviewers assessing the same applicants can, and do, come to widely differing judgements about them. Moreover, the effectiveness of interview judgements in predicting future performances also falls far short of the mark. Why then, do intelligent people, aware of the fallibility of the interview, still use it as one of the central tools of selection? The answer, of course, lies in the high perceived validity of the interview. Candidates like to be seen and selectors like to see them. It provides an opportunity to evaluate the 'public face' of the candidate appearance, manner and speech - and where more than one interviewer is involved, it diminishes accusations of unfairness, as the chances of individual prejudices are seen to be reduced.

In my view, the interview has a part to play in selection where the information gained from it is such as to enable the assessors to make a better selection decision than would otherwise have been the case. That means that the qualities required in a successful candidate have been clearly identified so that the committee knows what it is looking for. It means that the interviewing should be systematic, comprehensive and unbiased. It means that the candidate, not the interviewer, should be talking most of the time. It means that questions should be intelligently put, the answers probed and opportunities given for developing them. It means that the candidate should be made to feel as comfortable as possible so that he or she feels able to communicate as freely and effectively as the circumstances allow. It means that the assessors' minds should be open throughout and that the interview is not used as a means of simply confirming a previously formed judgment. In a panel, it means that there should have been some prior discussion about the candidate's application so that agreement is reached as to which particular areas to probe, and as to how the coverage will be divided between the assessors. It means that CVs should have been read thoroughly before the interview (not skimmed in the five minutes between candidates, and then scanned as the questioning proceeds).

In order to make good selection decisions, you have to have the fullest possible relevant information, so that judgements will be made on the basis of evidence and not on intuition, gut feel or bias. Interviewing, as I have suggested, is a fairly vulnerable, albeit much loved, method of selection.

To improve its efficiency, and ensure that the information obtained is what is needed, interviewers really should be trained. It is not enough to assume that men and women, howsoever intelligent, professionally competent and charming, will necessarily turn out to be effective interviewers. It is equally untenable to assume that a mysterious chemical fusion will occur in an interviewing panel, so that all its members are thinking along coherent and similar lines, and that each understands the implications of the questions posed by another panel member.

Advisory appointments committees are constrained in a number of ways. Because they are set up by statutory instrument they are subject to a very rigid formula, but this at least introduces a degree of standardization and ensures that relevant interested parties are represented. Each committee is made up of a lay chairman, two district representatives (a lay member of the Health Authority and a specialist medical representative) and medical representatives of the college, university and region. If run correctly, each interviewer will be restricted to his or her specific role and should not poach on anybody else's territory, but the very rigidity of the format does make it difficult to get a free flow of information from the applicant and makes great demands on the skills of the interviewers. It is my contention that, far too often, the committee members simply do not have those skills and that time is wasted on irrelevant, ineffectual and, occasionally, illegal questioning.

Quite apart from my reservations about the system and the standard of interviewing to be met at present, I have a further concern, and that is that many of the qualities required now in an effective consultant will not readily be identifiable, even in a well-conducted panel interview. It seems to me that, in looking for someone to provide a service in a particular discipline, a variety of essential qualities are sought. The appointed candidate must be able to demonstrate clinical competence at the highest level, and there will be evidence from a variety of sources - including the grapevine, references and publications - which may begin to answer questions on this point. Beyond that, 
however, the new consultant must be able to take on demanding managerial responsibilities and to demonstrate financial, organizational and administrative skills which have had perhaps only a vestigial relevance in his or her career to date. (This is why advisory appointments committees all too often fall back on the hypothetical questions 'what would you do if your budget were cut' and so forth).

There is a clear failing in the medical training system in that this crucial aspect of seniority is virtually ignored and that doctors are supposed to develop management skills through some sort of osmosis. It is true that there is now some awareness of this lacuna, and that some senior registrars do have the opportunity to attend short management skills courses, such as those run by the King's Fund College, the Royal College of Physicians and the NHS Training Authority, but this is no real substitute for a gradual building up of such expertise, in tandem with appropriate training, throughout a career. Imagine how industry and commerce would respond if someone, at thirty-five or forty, was suddenly appointed to a position of Department Head, responsible for a budget, for the staff and productivity of his department, and for liaising with the heads of other departments in the organization without having had any serious prior preparation.

Training, therefore, is inadequate, so advisory appointments committees are faced with the problem of trying to identify expertise, or at least potential, in this critical area. The interview, if carried out properly, may help, but it is probably not enough. Assessors need to have rather more information at their disposal in order to be able to make sound decisions based on evidence (that is, not intuition, hearsay or any prejudging of the scenario). The extended selection approach, known as the 'assessment centre' has been adopted successfully to deal with this question of identifying candidates' potential over a range of qualities; in particular, when there may be inadequate 'historical' information available to help those making selection decisions. An assessment centre would typically make use of a range of selection tools, including fairly in-depth interviewing (carried out on a one-to-one basis, a series of individual interviews yields very much more information than a panel would) but including also relevant tests and exercises designed to throw light on different areas which are important to the job under consideration. A group task - perhaps a Committee exercise - may well help to identify inter-personal qualities, the ability to organise priorities and to persuade without antagonising. There may be a place for psychological tests, looking perhaps at aspects of personality. One might wish to include a specially devised exercise, designed to explore grasp of the budgetary implications of a situation. The information derived from such a procedure, taking perhaps a day of the candidate's time, could then go to the final advisory appointments committee, whose members would then have a great deal more relevant material at their disposal which should allow them to make confident recommendations to the Regional Health Authority.

Naturally, there would be costing considerations to consider, but bearing in mind the cumbersome nature of the present long drawn out process and the true price to be paid when the wrong candidate is appointed, it may be thought worthwhile introducing some, at least, of these ideas. It seems unfortunate that medicine should not make use of some of the procedures which have been developed in order to improve the quality of selection decisions. These consultant appointments are so important. Clearly, the job is a highly responsible one, demanding a sophisticated combination of skills, and the present system does not seem fully to allow for these to be adequately identified. I think there is a case for developing appropriate selection procedures to help people to do that but it is clear, too, that the committee will continue to have some role to play, in order to ensure that the different user interests are adequately represented.

That being the case, the importance of good interviewing skills, and the presence of trained members on these committees should, I think, be acknowledged. If people are taught to use effectively the time that they do have with each candidate then that, in itself, will be a real improvement. Perhaps, eventually, the system of medical selection will be modified to allow for the introduction of some new procedures which should help assessors to identify the qualities that they are seeking in their candidates. The National Health Service is a huge employer of personnel and its methods should really be in the forefront of progress, not trailing behind, as they seem to be at present, in some sort of lumbering Edwardian complacency. 